\title{
The effect of a repeated intensive programme in patients with mid-stage Huntington's disease
}

\author{
Dagmar Pavlů ${ }^{1, *}$, Irena Opatrná-Novotná ${ }^{1}, J_{a n}$ Smyčka $^{2}$, David Pánek $^{1}$
}

\author{
1 Faculty of Physical Education and Sport, Charles University, Prague, Czech Republic \\ 2 Center for Theoretical Study, Charles University, Prague, Czech Republic \\ * Corresponding author: pavlu@ftvs.cuni.cz
}

\begin{abstract}
The purpose of the study was to evaluate the effect of a repeated 1-week intensive programme in patients with mid-stage Huntington's disease on stability and quality of life. 12 patients completed two 1-week programmes, separated by a one-year interval. Each programme consisted of a 120-minute intervention in the form of a fitness exercise, procedures targeting static and dynamic postural stability, procedures of respiratory physiotherapy and orofacial region therapy. The patient completed a total of 4 evaluations using the Sit to Stand Test, Timed up and Go Test and completed the quality of life SF-36 questionnaire. Statistically significant changes have been shown in the Sit-and-stand test in both years. Weaker but still significant changes were found in the TUG test only in the first year, while there was improvement in the second intervention year that was not statistically significant. Evaluation of the quality of life suggested a positive influence of physical activity in the dimensions: restriction caused by emotional problems, somatic pain and change of health. Our results suggest that a repeated, intensive one-week intervention can have a positive influence on postural stability and can contribute to the improvement of some quality of life dimensions in patients with mid-stage HD.
\end{abstract}

\section{KEYWORDS}

quality of life; Huntington's disease; TUG, SF-36, Sit-to-stand; intensive programme

DOI

$10.14712 / 23366052.2021 .8$

(c) 2021 The Authors. This is an open-access article distributed under the terms of the Creative Commons Attribution License (http://creativecommons.org/licenses/by/4.0), which permits unrestricted use, distribution, and reproduction in any medium, provided the original author and source are credited. 


\section{INTRODUCTION}

Huntington's disease (HD) is an autosomal dominant neurodegenerative disorder characterized by a progressive course, usually including motor, cognitive and psychiatric disturbances (Walker, 2007; Munoz-Sanjuan, Bates, 2011). The patient's age at the start of the disease most commonly corresponds to the fourth life decade (Chaganti, McCusker, Loy, 2017), its duration is between 15-20 years. In connection with diagnostic testing the prevalence of HD has increased in recent years, and amounts to 2.71 per 100,000 inhabitants worldwide, being significantly lower in the Asian population $(0.40$ per 100,000), compared to a prevalence of 5.70 per 100,000 in Western Europe, North America and Australia (Pringsheim et al., 2012; Sheharyar, Strong, Quarrell, 2016).

Since 1996 we have witnessed a growing number of publications on HD, mostly in the fields of neurosciences and neurology, further in the fields of psychiatry, genetics and molecular biology (Barboza, Ghisi, 2018), other specialties being rehabilitation and physiotherapy (e.g. Quinn, Busse, 2017; Drew et al., 2019; Quinn et al., 2020; Busse, et al. 2008). The latter are concerned with finding methods that would influence and/or slow down the increase of HD symptoms. Even though physiotherapy is recommended as one of the treatment, methods in HD reliable studies investigating its efficacy are still missing (Zinzi et al., 2007). As Huntington's disease is limiting, progressive and probably responsible for a set of changes in behaviour, social competency and, last but not least, quality of life (Silva, Lindau, Giacheti, 2015) methods are also being looked for that could positively influence quality of life.

In our study we present a 1-week intense programme we have proposed and repeatedly implemented in a small group of patients with mid-stage Huntington's disease and subsequently evaluated regarding its influence on static and dynamic stability and quality of life. We were interested in whether even a short, but intense programme could contribute to slowing down the increase of some symptoms in HD.

\section{MATERIALS AND METHODS}

\section{Subjects}

We performed a descriptive intervention study including 12 patients ( 6 men and 6 women) with mid-stage Huntington's disease. Patients aged between $26-55$ years old were included in the study based on recommendation by a physician and the inclusion criteria that included: voluntary participation in the study, aged above 18 years old, both sexes - males and women, disease stage - mid-stage, absence of severe psychiatric disorders, absence of severely damaged general cognitive functions, absence of orthopaedic or traumatology disturbances, and absence of acute diseases. All participants in the programme and their caretakers provided written consent to participate in the programme.

\section{Intervention}

Patients attended a 1-week intensive physiotherapy programme (6 days in 2019) and, after one year, participated in the same programme (in 2020), also lasting 6 days. In the period between the programmes, no other programmes were organized for the 
patients, and all performed their common accustomed activities as before initiation of the first week of the intensive programme.

The weekly programme in both years consisted of the application of intensive physiotherapy methods, each day 60 minutes in the morning and 60 minutes in the afternoon hours. The physiotherapy programme was completed with music therapy lasting 60 minutes and occupational therapist interventions, lasting 30 minutes in the morning and 30 minutes in the afternoon hours.

The physiotherapy programme included simple and special procedures that were distributed as follows: fitness training 30 minutes in the morning and then 30 minutes of methods influencing static and dynamic postural stability, in the afternoon $15 \mathrm{~min}$ utes of respiratory physiotherapy methods, 15 minutes of therapy focussing on the orofacial region, and 30 minutes of postural therapy. The most commonly employed elements were based on the PNF concept (Adler, Beckers, Buck, 2008), the sensorimotor training ( Janda et al., 2019), the Brügger concept (Pavlü, 2017) and the manual therapy concept (Lewit, 2009), but also common elements of fitness exercises and breathing therapy. Some of the methods were implemented in the form of individual physiotherapy and some in the form of exercises in small groups.

\section{Outcome measures}

To evaluate static and dynamic postural stability 2 simple tests have been selected that were performed in all subjects on the first and last days of the intensive programme. To evaluate the quality of life the SF-36 quality of life test was used, performed also on the first and last days of the programme.

\section{Sit to stand test}

The Sit to Stand test (Bohannon, 2011; Mong, Teo, Ng, 2010) is used to test dynamic postural stability and lower extremities strength of the patient. The test requires only the use a chair with a backrest, and a stopwatch to measure time. The test starts with the patient sitting on the chair with his back rested. Part of the test is measurement of the time in which the subject is able to stand up and sit back on the chair again. Our evaluation used a modified version with 3 repetitions.

\section{Timed up and go test}

Timed Up and Go (Nordin, Rosendahl, Lundin-Olsson, 2006) is a simple test used to evaluate mobility of the tested subject, but also the possibility of fall, a static and dynamic stability. As part of the test in which the time is measured the tested subject needs to get up from a chair, walk $3 \mathrm{~m}$, turn around and return back to the sitting position on the chair.

\section{SF-36}

Patient perception of the quality of life was evaluated using the Czech version of the SF-36 questionnaire (Ware, Sherbourne, 1992; Sobotík, 1998) that consists of 36 questions, divided into and assessing 8 basic dimensions +1 dimension, i.e. physical activity, restriction of physical activity, restriction caused by emotional problems, vitality, overall mental health, social activity, somatic pain, overall perception of health and change of health. 


\section{Statistical analysis}

We used the paired one-sided Wilcoxon test to test the effect of the intervention in the form of the sit-to-stand test and timed-up-and-go test, to evaluate the standardized effect in both tests the Cohen's D for paired design was used. The analyses were performed using the R 3.5.3 environment (R Core Team, 2019) and with the aid of the lsr library (Navarro, 2015). Real significance was determined using the following bounds $\mathrm{d}=0.2-0.49$ (small effect), $\mathrm{d}=0.5-0.79$ (moderate effect), $\mathrm{d} \geq 0.8$ (large effect).

In the SF-36 quality of life questionnaire the TS score was calculated (Transformed Scales Score).

\section{RESULTS}

\section{Sit to stand test}

The intensive programme resulted in statistically significant improvement in the sitto-stand test, both in the years 2019 and 2020 ( $\mathrm{p}=0.013$ or $\mathrm{p}=0.006$, respectively) in which the programme was implemented, even when the Bonferroni correction for multiple comparisons was considered ( $\mathrm{p}=0.026$ or $\mathrm{p}=0.012$, respectively). In 2019 and 2020 moderate $(D=0.63)$ or large $(D=0.82)$, respectively, standardized effects of the intervention were obtained. The median of improvement in the sit-and-stand test was $1.75 \mathrm{~s}$ in 2019 and $1.60 \mathrm{~s}$ in 2020 (Graph 1a, Graph 1b).

\section{Timed up and go test}

In the timed up and go test there was improvement in both years the programme was implemented. In 2019 the improvement was marginally significant $(p=0.071)$. Improvement in 2020 was significant $(\mathrm{p}=0.034)$, or marginally significant when the correction for multiple comparisons was considered ( $\mathrm{p}=0.068$ ). In 2019 the standardized effect was weak $(\mathrm{D}=0.19)$ and in 2020 moderate $(\mathrm{D}=0.62)$. The median of improvement in the up-and-go test was $0.75 \mathrm{~s}$ in 2019 and $0.37 \mathrm{~s}$ in 2020 . The result from 2019 is a reflection of the fact that most patients experienced mild improvement, but two of them had relatively marked deterioration (Graph 2a, Graph 2b).

\section{Quality of life - SF-36}

Quality of life evaluation using the SF-36 questionnaire logically demonstrated deteriorations in the dimensions that are related to disease progression, but in the case of three dimensions - Restriction caused by emotional problems, Somatic pain and Change of health - there was improvement in both weeks (repeatedly in both 2019 and 2020) of the administered intervention (Graph 3a, Graph 3b).

\section{DISCUSSION}

The objective of the presented study was to evaluate the effect of the repeated 1-week intensive programme in patients with mid-stage Huntington's disease. To achieve this objective we administered an intensive physiotherapy programme complemented with occupational therapy and music therapy, the effects of this one-week intensive physiotherapy intervention may have a positive influence on the evaluated static and dynamic postural and quality of life. 

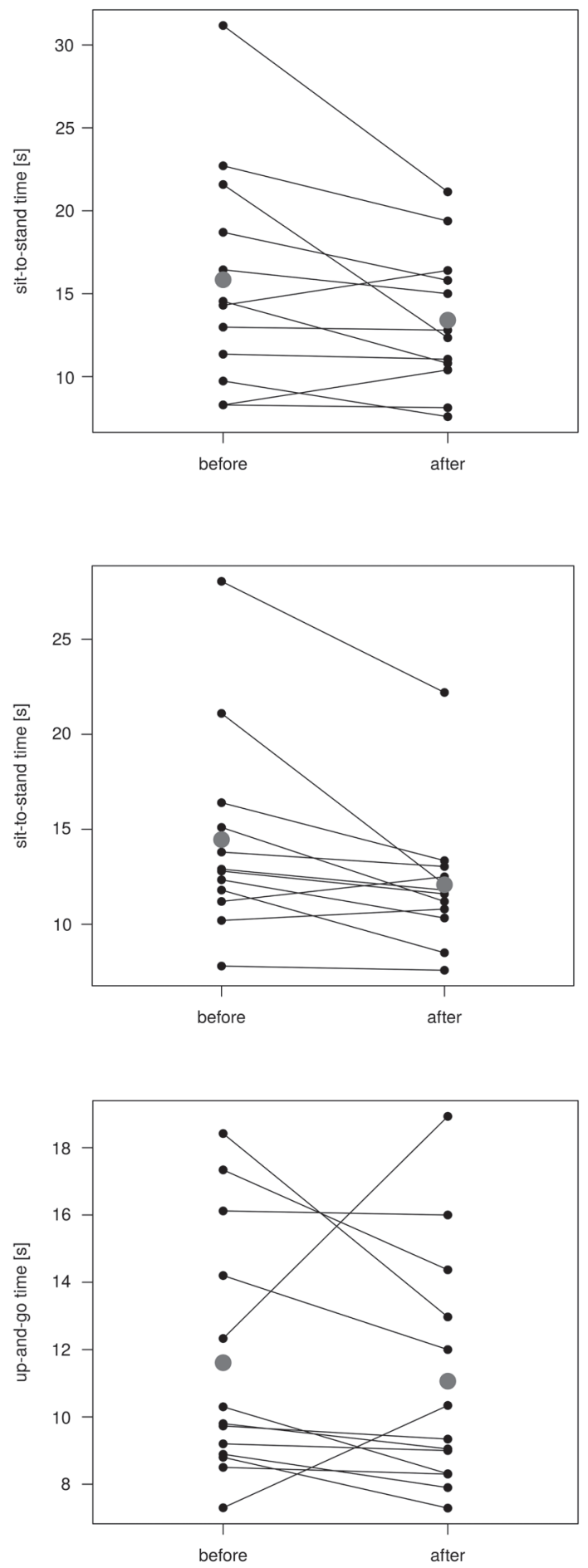

Graph 1a Timed Up and Go Test - comparison of results at the beginning and end of the intervention in 2019 for individual probands

Graph 1b Timed Up and Go Test - comparison of results at the beginning and end of the intervention in 2020 for individual probands

Graph 2a Sit - to Stand Test - comparison of results at the beginning and end of the intervention in 2019 for individual probands 


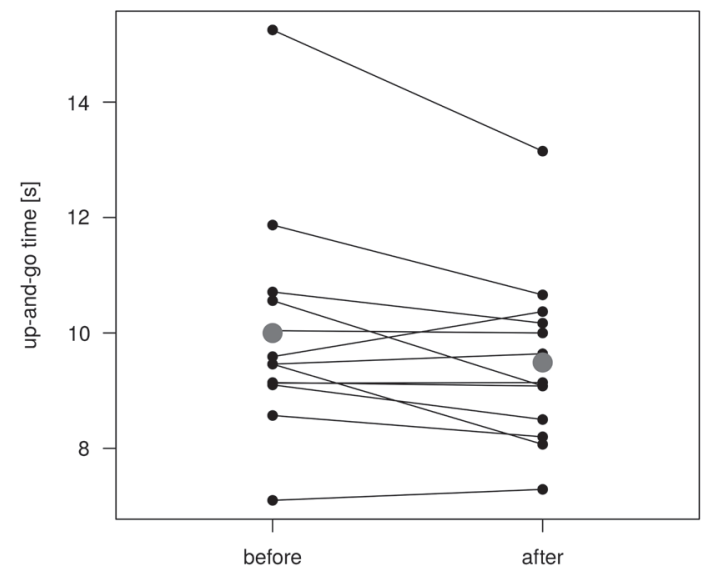

Graph 2b Sit - to Stand Test - comparison of results at the beginning and end of the intervention in 2020 for individual probands

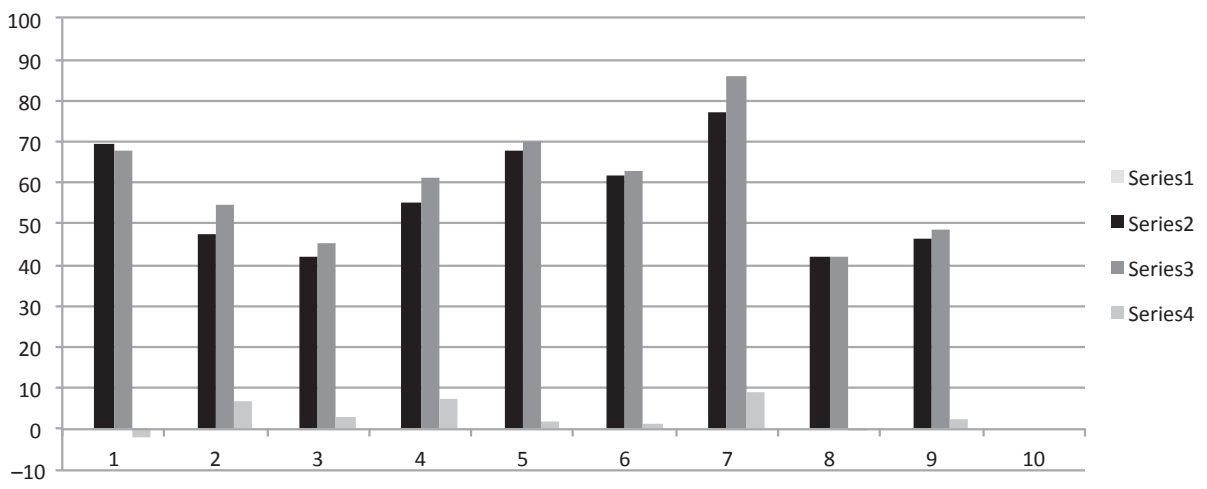

Graph 3a SF36 - comparison of results in 9 dimensions, at the beginning and end of the intervention in $2019(N=12)$

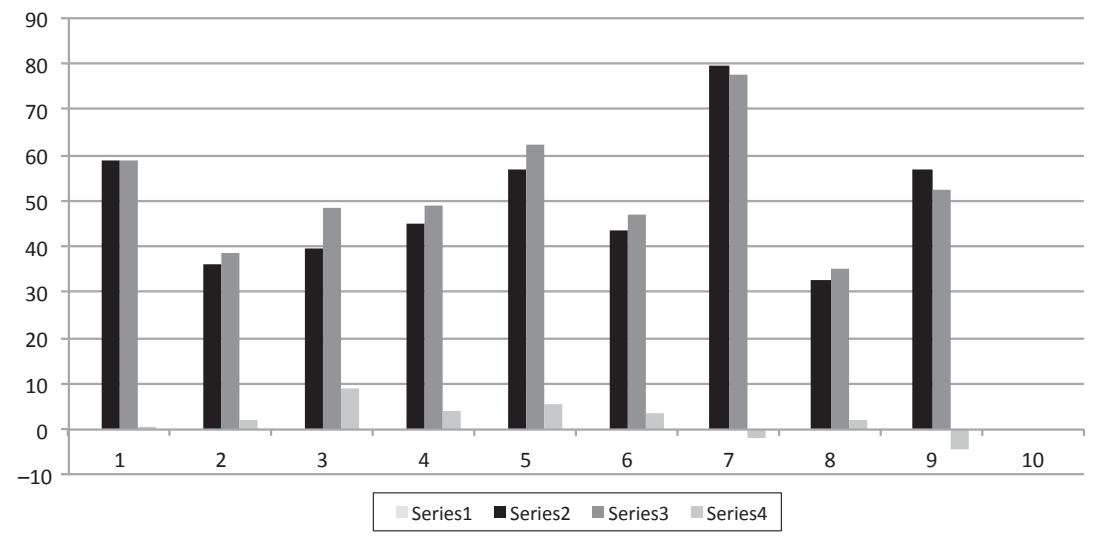

Graph 3b SF36 - comparison of results in 9 dimensions, at the beginning and end of the intervention in $2020(N=12)$ 
The intervention programme applied in the study was composed based on our previous experience (Novotná, Nováková, Pavlů, 2019; Novotná, Pavlů, 2019) where we succeeded in influencing some neurological symptoms in patients with mid-stage Huntington's disease, primarily with targeted therapy. The therapy influenced mobility and ability to walk, the ability to cope with ADL, including the rehearsal of swallowing with orofacial therapy.

The intervention procedures we used correspond to the recommended or already applied procedures in a number of other studies. Aerobic exercise performed separately or in combination with resistance training as recommended e.g. by Quinn et al. (Quinn et al., 2020) had the form of the fitness training in our study, as was the case of walk training. As an essential element to include, in agreement with a number of other authors (e.g. Fritz et al., 2017) are procedures of respiratory physiotherapy. In view of time limitations, however, our study did not evaluate respiratory parameters.

Several previous studies demonstrated or suggested positive effects of an intensive physiotherapy/rehabilitation programme (Piira et al., 2013). Specific programmes, however, were implemented over the course of very long periods of time - 1-2 years. Our study is unique in pointing to the possibility to obtain a positive effect on repeated occasions consisting in influencing the static and dynamic postural stability in a short time period - one week.

To evaluate stability we used only two Sit to stand test and TUG that we consider to be easily implemented and also appropriate in view of the common patient daily activities. Studies concerned with evaluation of the training effect on motor function often use, in addition to the tests we have used, the Berg Balance Scale (Mueller, Petersen, Jung, 2019), the Six Minute Walk Test (Piira et al., 2013) that are unequivocally suitable outcome measures, but their implementation requires more time. The tests we have chosen can be well accomplished in a situation when the entry measurement must be managed during the first day of initiation of the intervention as part of our programmes as well as a final measurement on the last day of the programme.

To evaluate quality of life we used the SF-36 questionnaire that appears to be suitable and is recommended also for patients with various stages of $\mathrm{HD}$ and exhibits convergent validity and reliability for patients and care takers (Aileen et al., 2004; Mestre et al., 2018). It was not the primary objective of our study to evaluate the quality of life of its participants as is the case in commonly available studies (e.g. Dorey et al., 2016). Instead we evaluated possible effects of an intensive intervention on maximizing functional mobility of patients, and thereby aim to support their quality of life. The results have shown that most of the dimensions evaluated in the quality of life questionnaire showed deterioration or no change, which can rather be expected in the setting of continuing disease progression, but nonetheless we have still repeatedly demonstrated improvement in the case of three evaluated dimensions that reflect the influence of movement activity in both 2019 and 2020.

Our work has some limitations. The study included a relatively small number of subjects and had no control group, similar to a number of other studies of patients with the diagnosis of M. Huntington (e.g. Dawes et al., 2015; Kloos et al., 2012). Clinical studies, however, often include patients with relatively small samples due to difficult access to study subjects / patients who would exhibit the same or a similar specific set of symptoms, which is also a problem in the case of HD. But in spite of the above we 
regard the considerable homogeneity of our sample to be a strong aspect, and this can also be said about the fact that all patients included in the study attended both weekly intensive programmes and completed the study within 2 years. Our results should, however, be considered with some caution as the effect was evaluated based on the use of only two tests and a quality of life questionnaire. Future studies should thus attempt to continue our work in a larger sample and assess other aspects related to postural stability and quality of life.

\section{CONCLUSIONS}

Our results suggest that repeated one-week intensive physiotherapy intervention can positively influence both the static and dynamic postural stability in patients with mid-stage Huntington's disease and can also positively influence some quality of life dimensions. In view of the low number of patients, however, caution is necessary when interpreting the results.

\section{REFERENCES}

Adler, S., Beckers, D., Buck, M. (2008). PNF in Practice: An Illustrated Guide 3rd Edition. Stuttgart: Springer.

Aileen, K. H. O., Robbins, A. O. G., Walters, S. J., Kaptoge, S., Sahakian, B. J., Barker, A. R. (2004). Health-related quality of life in Huntington's disease: a comparison of two generic instruments, SF-36 and SIP. Mov. Disord., 19(11), 1341-1348.

Barboza, L. A., Ghisi, N. C. (2018). Evaluating the current state of the art of Huntington disease research: a scientometric analysis. Brazilian Journal of Medical and Biological Research, 51(3), e6299, doi.org/10.1590/1414-431X20176299.

Bohannon, R. W. (2011). Test - Retest Reliability of the Five - Repetition Sit - to - Stand Test: A Systematic Review of the Literature Involving Adults. Journal of Strenght and Conditioning Research [online]. 25(11), 3205-3207, doi.org/10.1519/JSC.0b013e318234e59f.

Busse, M. E., Khalil, H., Quinn, L., Rosser, A. E. (2008). Physical Therapy Intervention for People With Huntington Disease. Phys. Ther., 88(7), 820-831.

Dawes, H., Collett, J., Debono, K., Quinn, L., Jones, K., Kelson, M. J., Simpson, S. A., Playle, R., Backx, K., Wasley, D., Nemeth, A. H., Rosser, A., Izardi, H., Busse, M. (2015). Exercise testing and training in people with Huntington's disease. Clin. Rehabil., 29(2), 196-206.

Dorey, J., Clay, E., Khemiri, A., Belhadj, A., Cubillo, P. T., Toumi, M. (2016). The quality of life of Spanish patients with Huntington's disease measured with H-QoL-I and EQ-5D. Journal of Market Access \& Health Policy, Oct 13, 4, doi: 10.3402/jmahp.v4.27356.

Drew, C. J. G., Quinn, L., Hamana, K., Williams-Thomas, R., Marsh, L., Dimitropoulou, P., Playle, R., Griffin, B. A., Kelson, M., Schubert, R., Muratori, L., Reilmann, R., Rosser, A., Busse, M. (2019). Physical Activity and Exercise Outcomes in Huntington Disease (PACEHD): Protocol for a 12-Month Trial Within Cohort Evaluation of a Physical Activity Intervention in People With Huntington Disease. Phys. Ther., Sep 1, 99(9), 1201-1210.

Fritz, N. E., Rao, A. K., Kegelmeyer, D., Kloos, A., Busse, M., Hartel, L., Carrier, J., Quinn, L. (2017). Physical Therapy and Exercise Interventions in Huntington's Disease: A Mixed Methods Systematic Review. J. Huntingtons Dis., 6(3), 217-235.

Chaganti, S. S., McCusker, E. A., Loy, C. T. (2017). What do we know about Late Onset Huntington's Disease? Journal of Huntington's Disease, 6(2), 95-103. 
Janda, V., Vávrová, M., Herbenová, A., Veverková, M. (2019). “Sensori motor training”. In: C. Liebenson (Ed.), Rehabilitation of the Spine: A Patient-Centered Approach. 3rd Ed., Publisher: Wolters Kluwer Health, p. 564-580.

Kloos, A. D., Kegelmeyer, D. A., White, S. E., Kostyk, S. K. (2012). The impact of different types of assistive devices on gait measures and safety in Huntington's disease. PLoS One, $7(2)$, e30903.

Lewit, K. (2009). Manipulative Therapy: Musculoskeletal Medicine. 1st Edition. Publisher: Churchill Livingstone.

Mestre, T. A., Carlozzi, N. E., Ho, A. K., Burgunder, J. M., Walker, F., Davis, A. M., Busse, M., Quinn, L., Rodrigues, F. B., Sampaio, C., Goetz, C. G., Cubo, E., Martinez-Martin, P., Stebbins, G. T. (2018). Quality of Life in Huntington's Disease: Critique and Recommendations for Measures Assessing Patient Health-Related Quality of Life and Caregiver Quality of Life. Mov. Disord., 33(5), 742-749.

Mong, Y., Teo, T. W., Ng, S. S. (2010). 5-Repetition Sit-to-Stand Test in Subjects With Chronic Stroke: Reliability and Validity. Physical Medicine and Rehabilitation, 91(3), 407-413.

Mueller, S. M., Petersen, J. A., Jung, H. H. (2019). Exercise in Huntington's Disease: Current State and Clinical Significance. Tremor Other Hyperkinet. Mov., 4(9), 601.

Munoz-Sanjuan, I., Bates, G. P. (2011). The importance of integrating basic and clinical research toward the development of new therapies for Huntington's disease. J. Clin. Invest., 121(2), 476-483.

Navarro, D. J. (2015). Learning statistics with R: A tutorial for psychology students and other beginners (Version 0.5). Adelaide: University of Adelaide.

Nordin, E., Rosendahl, E., Lundin-Olsson, L. (2006). Timed „Up \& Go“ Test: Reliability in Older People Dependent in Activities of Daily Living-Focus on Cognitive State. Physical Therapy, 86(5), 646-655.

Novotná, I., Nováková, T., Pavlů, D. (2019). Swallowing disorders in patients diagnosed with Huntington's disease - possibilities of medical rehabilitation intervention (in czech). Rehabilitácia, 56(1), 62-72.

Novotná, I., Pavlů, D. (2016). Huntington's disease - Are there comprehensive rehabilitation options? (in czech) Rehabil. Fyz. Lék., 23(1), 48-54.

Pavlů, D. (2017). „Brügger concept“. In: K. Řasová (Ed.), Neurorehabilitation of People with Impaired Mobility - Therapeutic Interventions and Assessment Tools. Prague: 3Th Medical Faculty, Charles University, pp. 194-201.

Piira, A., Van Walsen, M. R., Mikalsen, G., Oie, L., Frich, J. C., Knutsen, S. (2014). Effects of a Two-Year Intensive Multidisciplinary Rehabilitation Program for Patients with Huntington's Disease: a Prospective Intervention Study. Plos Curr., Nov 25, 6. doi: 10.1371/currents.hd.2c56ceef7f9f8e239a59ecf2d94cddac.

Piira, A., Van Walsen, M. R., Mikalsen, G., Nilsen, K. H., Knutsen, S., Frich, J. C. (2013). Effects of a One Year Intensive Multidisciplinary Rehabilitation Program for Patients with Huntington's Disease: a Prospective Intervention Study. Plos Curr., 5. doi: 10.1371 /currents.hd.9504af71e0d1f87830c25c394be47027.

Pringsheim, T., Wiltshire, K., Day, L., Dykeman, J., Steeves, T., Jette, N. (2012). The incidence and prevalence of Huntington's disease: a systematic review and meta-analysis. Movement Disorders, 27(9), 1083-1091.

Quinn, L., Busse, M. (2017). The role of rehabilitation therapy in Huntington disease. Handb. Clin. Neurol., 144, 151-165. doi: 10.1016/B978-0-12-801893-4.00013-4.

Quinn, L., Kegelmeyer, D., Kloos, A., Rao, A. K., Busse, M., Fritz, N. E. (2020). Clinical recommendations to guide physical therapy practice for Huntington disease. Neurology, Feb 04, 94(5), 217-228. 
R Development Core Team (2019). R: A language and environment for statistical computing. Vienna, Austria: R Foundation for Statistical Computing. URL: https://www.R-project. org/.

Sheharyar, S. B., Strong, M., Quarrell, O. W. J. (2016). The global prevalence of Huntington's disease: a systematic review and discussion. Neurodegenerative Disease management, 6(4). doi.org/10.2217/nmt-2016-0008.

Silva, C. S., Lindau, T. A., Giacheti, C. M. (2015). Behavior, social competence and quality of life in Huntington's Disease. Revista CEFAC, 17(6). doi: 10.1590/1982-0216201517621414.

Sobotík, Z. (1998). Zkušenosti s použitím předběžné české verze amerického dotazníku o zdraví (SF-36). Zdravotnictví v České republice, 1(1-2), 50-54.

Walker, F. O. (2007). Huntington's disease. Lancet, 369(9557), 218-228. doi: 10.1016/S0140 $-6736(07) 60111-1$.

Ware, J. E., Sherbourne, C. D. (1992). The MOS 36 - Item Short Form Health Survey (SF-36): I. Conceptual Framework and Item Selection. Medical Care, 30(6), 473-483, https:// www.jstor.org/stable/3765916.

Zinzi, P., Salmaso, D., De Grandis, R., Graziani, G., Maceroni, S., Bentivoglio, A., Zappata, P., Frontali, M., Jacopini, G. (2007). Effects of an intensive rehabilitation programme on patients with Huntington's disease: a pilot study. Clinical Rehabilitation, 21(7), 603-613.

\section{Author Contributions:}

DPav, DPan and ION contributed to the initial development of research, its preparation and implementation, ION led the interventions and gathered the data, and JS contributed to statistical analysis. DP was the main author and is responsible for the overall study content.

\section{Institutional Review Board Statement:}

The study was conducted according to the guidelines of the Declaration of Helsinki, and approved by Ethics Committee (EC of Charles University, FTVS, EK 264/2018). Informed Consent Statement: Informed consent was obtained from all subjects involved in the study. 